\title{
ÉPOCAS DE APLICAÇÃO DE DESSECANTES NA CULTURA DA SOJA: QUALIDADE FISIOLÓGICA DE SEMENTES ${ }^{1}$
}

\author{
LUIZ HENRIQUE MARCANDALLI ${ }^{2}$, EDSON LAZARINI ${ }^{3}$, IGOR CRUZ MALASPINA ${ }^{4}$
}

\begin{abstract}
RESUMO - O presente trabalho teve como objetivo avaliar o efeito da aplicação de diferentes dessecantes aplicados em diferentes estádios reprodutivos na qualidade fisiológica de sementes de soja. O delineamento experimental utilizado foi em blocos casualizados com quatro repetições. Os tratamentos foram dispostos em um esquema fatorial, sendo que para a cultivar MSOY 6101, de ciclo super precoce, utilizou-se $3 \times 3 \times 5 \times 2$, dois dessecantes (glifosato e paraquat) e uma testemunha (sem dessecação), três estádios fenológicos $\left(\mathrm{R}_{6}, \mathrm{R}_{7}\right.$ e $\left.\mathrm{R}_{8}\right)$, cinco épocas de amostragem (2, 4, 6, 8 e 10 dias após aplicação) e duas posições de avaliação na planta (ápice e base). Para a cultivar MG/BR 46 (Conquista) de ciclo precoce, utilizou-se $3 \times 2 \times 5 \times 2$, sendo nesse caso somente dois estádios fenológicos $\left(\mathrm{R}_{7}\right.$ e $\mathrm{R}_{8}$ ). Diante dos resultados obtidos pode-se concluir que o glifosato influencia negativamente a qualidade fisiológica de sementes, principalmente, quando avaliada por meio do teste de comprimento de raiz. O herbicida paraquat não altera a qualidade fisiológica das sementes. As sementes obtidas com aplicação de dessecantes no estádio $\mathrm{R}_{6}$ são de qualidade fisiológica inferior às obtidas com aplicação nos estádios $\mathrm{R}_{7}$ e $\mathrm{R}_{8}$.
\end{abstract}

Termos para indexação: colheita, dessecação, glifosato, paraquat.

\section{TIMING OF DESICCANT APPLICATION IN SOYBEANS: PHYSIOLOGICAL QUALITY OF SEEDS}

\begin{abstract}
The objective of this study was to evaluate the effect of different desiccants on the physiological quality of soybean seeds when applied to different reproductive stages. The experiment was conducted in the 2005/06 crop season using a randomized block design of four repetitions and two varieties. For the very early maturing MSOY 6101 variety, a factorial 3x3x5x2 design was used, with two desiccant treatments (glyphosate and paraquat) and a control (no desiccation), applied at three growth stages $\left(\mathrm{R}_{6}, \mathrm{R}_{7}\right.$ and $\left.\mathrm{R}_{8}\right)$, with five sampling times $(2 ; 4 ; 6 ; 8$ and 10 days after application) and two evaluation positions on the plant (apex and base). The early

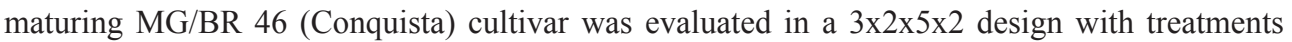
applied at only two growth stages $\left(\mathrm{R}_{7}\right.$ and $\left.\mathrm{R}_{8}\right)$. The results showed that glyphosate adversely affected physiological seed quality, mainly for root length, whereas paraquat caused no apparent effect. The seeds from desiccant applications in the $\mathrm{R}_{6}$ stage showed a lower physiological quality compared to those obtained from applications in the $R_{7}$ and $R_{8}$ stages.
\end{abstract}

Index terms: harvest, desiccation, glyphosate, paraquat.

${ }^{1}$ Submetido em 06/05/2010. Aceito para publicação em 17/09/2010.

${ }^{2}$ Eng. Agr., Mestrando em Ciências - Energia Nuclear na Agricultura e Ambiente - CENA/USP - Lab. de Nutrição Mineral de Plantas - Av. Centenário, 303. Piracicaba - SP 13400-970, luizmarcandalli@cena.usp.br
${ }^{3}$ Professor Doutor do Dep. de Fitotecnia Tecnologia de Alimentos e Sócio-Economia - Av. Brasil, 56 Cx. Postal - 31, Ilha Solteira - SP 15385-000 lazarini@agr.feis.unesp.br

${ }^{4}$ Eng. Agr., Mestre em Agronomia, igormalaspina@yahoo.com.br 


\section{INTRODUÇÃO}

O Brasil ocupa a posição de segundo maior produtor mundial de soja, apresentando números de 57,1 milhões de toneladas produzidas na safra 2008/09, em 21,7 milhões de hectares (ha) cultivados (Embrapa, 2009).

A dessecação é uma prática utilizada nas áreas de produção de grãos, com o objetivo de controlar as plantas daninhas ou uniformizar as plantas com problema de haste verde e/ou retenção foliar (Embrapa, 2005).

A tecnologia para a produção de sementes preconiza a realização da colheita no momento mais próximo possível da maturidade fisiológica. Entretanto, as sementes, de maneira geral, atingem a maturidade fisiológica com teores de água superiores a 30\%, não compatíveis com a tecnologia disponível para a colheita mecânica (Miranda et al.,1999). Estas estão sujeitas à perda da qualidade fisiológica desde a maturidade até o momento da semeadura. A deterioração manifesta-se no decorrer do tempo, ocasionando reflexos negativos no vigor. A rapidez com que ocorre a perda de qualidade das sementes após a maturidade fisiológica é função da espécie, da cultivar e das condições impostas às sementes no campo, após a colheita e durante as operações de beneficiamento e armazenamento.

Segundo Lacerda et al. (2003), o potencial de conservação de sementes de soja depende diretamente da qualidade fisiológica das mesmas no início do período de armazenamento, sendo intimamente relacionada ao momento da colheita. A semente contém genes que expressam o potencial produtivo da cultivar, uma vez que a qualidade superior implica numa série de características economicamente desejáveis como, sanidade, adaptação às condições adversas de clima e solo, assim como maior capacidade de germinação (Costa et al., 2003).

A maturação compreende uma série de alterações morfológicas, fisiológicas e funcionais, as quais ocorrem a partir da fertilização do óvulo, prosseguindo até o momento em que as sementes estão em condições para a colheita (Hamer, 1999). Na cultura da soja essa maturação é extremamente desuniforme, e durante este processo, verificam-se alterações na massa de matéria seca, teor de água, tamanho, germinação e vigor (Marcos Filho, 2005), além das alterações na composição química das sementes, ou seja, nos teores de carboidratos, proteínas, lipídios, entre outras (Delouche, 1971).

A semente de soja apresenta maturidade fisiológica caracterizada pelo máximo acúmulo de matéria seca, entre os $45 \%$ a $50 \%$ aproximadamente, de umidade. Isto ocorre geralmente quando as sementes (e também a vagem) tornam-se amarelas ou tenham perdido completamente a cor verde (Veiga et al. 2007).

$\mathrm{O}$ atraso da colheita, associado à variação da umidade relativa do ar, acarreta vários prejuízos às sementes, como o aumento das porcentagens de rachadura e enrugamento do tegumento, aumentando o processo de deterioração, em virtude de maior facilidade de penetração de patógenos e maior exposição do tecido embrionário ao ambiente.

Uma alternativa que pode ser empregada por produtores de soja para minimizar a deterioração da qualidade das sementes no campo é a aplicação de herbicidas dessecantes. A aplicação desses dessecantes é realizada quando a maioria das sementes está madura, com a finalidade de promover a secagem mais rápida das plantas e o aumento da uniformidade de maturação. Essa prática facilita a colheita, a obtenção de menores teores de impurezas e sementes de melhor qualidade, além da redução de perdas e do menor custo de secagem (Inoue et al., 2003).

A aplicação de dessecantes na cultura da soja é recomendada quando as plantas apresentam $80 \%$ de vagens amareladas e $20 \%$ de secas, com folhas amareladas (Bastidas et al., 1971), ou quando as vagens estão amarelando e $50 \%$ das folhas já estão amarelas (Fehr et al., 1977), ou ainda, quando os ramos e vagens estão marrons e as folhas caídas (Hammerton, 1972).

A dessecação pode proporcionar maior uniformidade de maturação da cultura, além de antecipar a colheita em alguns dias, obtendo assim, sementes de melhor qualidade fisiológica e sanitária (Lacerda et al., 2005).

Os herbicidas bipiridílios são considerados muito efetivos, pois são rapidamente absorvidos pelas plantas, mas não são translocados em quantidades suficientes para destruir as raízes (Gomes et al., 2003). Um exemplo clássico é o paraquat, herbicida de contato, inibidor do fotossistema I, que reduz drasticamente o teor de água da biomassa verde das plantas.

Outro herbicida bastante utilizado para a dessecação em áreas a serem utilizadas com semeadura direta das culturas é o glifosato. Este herbicida sistêmico, do grupo das glicinas, possui largo espectro de ação, é não-seletivo e utilizado em pós-emergência das plantas daninhas. Atua na inibição da enzima 5-enolpiruvil shiquimato3-fosfato ácido sintetase (EPSP), comprometendo a biossíntese de triptofano, aminoácidos aromáticos e de clorofila, provavelmente devido à inibição da síntese 
de AIA (ácido indolacético), alterando estruturas e provocando danos celulares irreversíveis, tais como a ruptura parcial do cloroplasto e a perda de água do retículo endoplasmático rugoso (Menezes et al., 2004).

Com o aumento do número de cultivo nas áreas agrícolas, visando maior rendimento por área, os ciclos de cultivo estão se tornando cada vez mais curtos e tendo a soja uma maturidade fisiológica desuniforme, o uso de dessecantes para antecipação da colheita, tem aumentado continuamente. Neste sentido, o presente trabalho teve como objetivo avaliar o efeito da aplicação de diferentes dessecantes aplicados em diferentes estádios reprodutivos na qualidade fisiológica de sementes de soja.

\section{MATERIAL E MÉTODOS}

O trabalho foi executado em duas etapas, uma no campo e outra em laboratório. A fase de campo foi realizada na Fazenda de Ensino, Pesquisa e Extensão da FE/UNESP, localizada no município de Selvíria - MS, com coordenadas geográficas $51^{\circ} 22^{\prime}$ de longitude Oeste e $20^{\circ} 22^{\prime}$ de latitude Sul, com aproximadamente $335 \mathrm{~m}$ de altitude, $1.370 \mathrm{~mm}$ de precipitação média anual e $23,5{ }^{\circ} \mathrm{C}$ de temperatura média anual.

O delineamento experimental utilizado foi em blocos casualizados com quatro repetições. Os tratamentos e avaliações foram dispostos em um esquema fatorial, avaliando separadamente duas cultivares (MSOY 6101 e MG/BR 46 (Conquista)), sendo que para a cultivar MSOY 6101 de ciclo super precoce utilizou-se o fatorial $3 \times 3 \times 5 \times 2$, dois dessecantes (glifosato e paraquat) e uma testemunha (sem dessecação), três estádios fenológicos de aplicação $\left(\mathrm{R}_{6}, \mathrm{R}_{7}\right.$ e $\left.\mathrm{R}_{8}\right)$, cinco épocas de amostragem após a aplicação dos dessecantes (2, 4, 6, 8 e 10 dias após) e duas posições de avaliações na planta (ápice e base). Para a cultivar MG/BR 46 (Conquista) de ciclo precoce, utilizouse $3 \times 2 \times 5 \times 2$, dois dessecantes (glifosato e paraquat) e uma testemunha (sem dessecação), dois estádios fenológicos de aplicação $\left(R_{7}\right.$ e $\left.R_{8}\right)$, devido essa ter apresentado um estádio $\mathrm{R}_{6}$ muito curto, que impossibilitou a aplicação dos dessecantes, cinco épocas de amostragem após a aplicação dos dessecantes (2, 4, 6, 8 e 10 dias após) e duas posições de avaliações na planta (ápice e base).

As parcelas experimentais constaram de 10 linhas de $15 \mathrm{~m}$, espaçadas de $0,45 \mathrm{~m}$, totalizando $67,5 \mathrm{~m}^{2}$, considerando-se como área útil as seis linhas centrais com $10 \mathrm{~m}$ de comprimento.
A cultura da soja foi instalada e conduzida de acordo com as recomendações da Embrapa (2005), no que se refere ao tratamento e inoculação das sementes, manejo de plantas daninhas, pragas e doenças.

A semeadura foi realizada em $29 / 11 / 2005$, sendo a emergência das plantas observada em 05/12/2005. Utilizou-se como densidade de semeadura 18 e 22 sementes por metro de sulco, respectivamente, para as cultivares MG/BR 46 (Conquista) e MSOY 6101. A adubação de semeadura constou de $150 \mathrm{~kg} \cdot \mathrm{ha}^{-1}$ da fórmula 08-28-16, baseada na análise de solo.

Para a aplicação dos herbicidas utilizou-se um trator equipado com pulverizador, com capacidade de 600 $\mathrm{L}$, com barras de $6 \mathrm{~m}$ equipadas com bicos tipo leque, espaçados de 0,5 m e calibrado para aplicação de volume de 200 L calda.ha ${ }^{-1}$. As aplicações dos dessecantes foram realizadas preferencialmente no período da manhã.

Para a identificação dos estádios de desenvolvimento nas respectivas cultivares foram feitas visitas periódicas à área experimental a partir do início da formação das sementes, e utilizando-se da descrição de Fehr et al. (1977). Na cultivar MSOY 6101 as aplicações ocorreram em 10/03/2006 $\left(R_{6}\right), 20 / 03 / 2006\left(R_{7}\right)$ e $29 / 03 / 2006\left(R_{8}\right)$ e para a cultivar MG/BR 46 (Conquista), em 20/03/2006 $\left(R_{7}\right)$ e 29/03/2006 $\left(R_{8}\right)$.

Após a aplicação dos dessecantes, em cada estádio, e em cada cultivar, foram feitas cinco amostragens por tratamento (época de amostragem), sendo 2, 4, 6, 8 e 10 dias após a aplicação dos dessecantes. Foram coletadas assim as sementes para as avaliações, de modo que, em cada amostragem coletou-se uma amostra com 60 plantas por parcela (10 plantas seguidas em cada linha da área útil de cada parcela), das quais se retirou as vagens da posição inferior da planta (base) e da superior (ápice), para as seguintes avaliações fisiológicas:

Teste de germinação: foi realizado segundo as Regras para Análise de Sementes (Brasil, 1992), com quatro subamostras de 50 sementes, utilizando-se como substrato rolo de papel tipo germitest, umedecido com água destilada na proporção de 2,5 vezes seu peso seco. Após a confecção dos rolos, estes foram embalados em sacos plásticos e mantidos em câmara de germinação, à temperatura constante de $25{ }^{\circ} \mathrm{C}$. A contagem foi realizada oito dias após a instalação do teste e os resultados expressos em porcentagem de plântulas normais.

Teste de envelhecimento acelerado: foi conduzido com quatro subamostras de 50 sementes. Foram utilizadas caixas plásticas transparentes com tampa (gerbox) com 
11 x 11 × 3 cm, adaptadas como minicâmaras, dentro das quais foram adicionados $40 \mathrm{~mL}$ de água destilada. Acima da água foi colocada uma tela e sobre a tela, em cada caixa, foram colocadas as sementes. Em seguida, as caixas plásticas foram levadas para a câmara do tipo BOD, regulada na temperatura de $42{ }^{\circ} \mathrm{C}$, onde permaneceram por 48 horas (Marcos Filho, 1999). Após esse período, as sementes foram colocadas para germinar conforme descrito no teste de germinação, e a contagem do número de plântulas normais foi realizada no quinto dia após a instalação do teste. Os resultados foram expressos em porcentagem de plântulas normais.

Teste de condutividade elétrica: a determinação da condutividade elétrica foi realizada utilizando-se duas amostras de 25 sementes. As amostras foram pesadas em balança de precisão e a seguir colocadas para embebição em recipiente plástico contendo $75 \mathrm{~mL}$ de água destilada, sendo mantidas em câmara-germinador à temperatura de $25{ }^{\circ} \mathrm{C}$, durante $24 \mathrm{~h}$ (Marcos Filho, 1999). Após esse período, procedeu-se a leitura da condutividade elétrica na solução de embebição, utilizando-se um condutivímetro digital, cujos resultados foram expressos em $\mu S \mathrm{~cm}^{-1} \cdot \mathrm{g}^{-1}$.

Teste de comprimento de raiz: a avaliação do comprimento de raiz foi realizada a partir de quatro subamostras de 20 sementes para cada tratamento. Utilizou-se como substrato rolo de papel tipo germitest, no qual as sementes foram distribuídas em duas linhas retas longitudinais. Após a confecção dos rolos, os mesmos foram embalados em sacos plásticos e colocados em germinador regulado a temperatura constante de 25 ${ }^{\circ} \mathrm{C}$ (Nakagawa, 1999). No $5^{\circ}$ dia após a instalação do teste, foi avaliado o comprimento de raiz das plântulas germinadas, sendo cada plântula medida separadamente e, em seguida, foi calculado o comprimento médio das raízes.

A análise estatística dos dados obtidos foi realizada com o auxílio do software SANEST (Zonta e Machado, 1991). Foram realizadas as análises de variância pelo Teste $\mathrm{F}$, verificando assim a significância dos tratamentos (dessecantes e estádio de aplicação) e das avaliações (épocas de amostragens e posição na planta). Para obtenção das diferenças estatísticas utilizou-se, para os tratamentos (dessecantes e épocas de aplicação) e para a avaliação (posição na planta), o teste de Tukey aos $5 \%$ de probabilidade. Na avaliação entre as épocas de amostragem utilizou-se o método de regressão polinomial para a obtenção das diferenças estatísticas.

\section{RESULTADOS E DISCUSSÃO}

Para a cultivar MSOY 6101, verificam-se diferenças significativas para estádio de desenvolvimento em todas as avaliações realizadas (Tabela 1), havendo também interação significativa para estádio de aplicação x época de amostragem nas avaliações de envelhecimento acelerado e comprimento de raiz; dessecantes x estádio de aplicação ou épocas de amostragens, para comprimento de raiz e efeito isolado de posição na planta avaliada, para avaliações de comprimento de raiz e condutividade elétrica e de dessecantes na avaliação do comprimento de raiz.

Quanto à porcentagem de germinação, verificou-se que os valores obtidos, em média, classificam a produção obtida como adequada para a comercialização como semente, pois conforme Embrapa (2005), a porcentagem mínima exigida como padrão para semente é de $80 \%$. Quando se avaliou as sementes obtidas nos estádios de desenvolvimento, verificou-se que as colhidas em $\mathrm{R}_{7}$ e $\mathrm{R}_{8}$, apresentaram maior porcentagem de germinação.

Gomes et al. (1982) observaram aumento na porcentagem de plântulas normais e redução nas plântulas anormais e mortas, quando os dessecantes foram aplicados nos estádios mais próximos da maturação fisiológica. No entanto, Whigham e Stoller (1979), trabalhando com três épocas de aplicação, verificaram que o paraquat, quando aplicado a quatro e três semanas antes da colheita, não prejudicou a germinação e vigor das sementes.

$\mathrm{Na}$ avaliação do vigor das sementes por meio do teste de envelhecimento acelerado, observou-se no desdobramento entre estádio de aplicação x época de amostragem (Tabela 2), que as sementes obtidas no tratamento $\mathrm{R}_{6}$, apresentaram, com exceção da última amostragem, menor vigor, principalmente, quando comparado com as sementes do tratamento $\mathrm{R}_{8}$. Entretanto, na avaliação da condutividade elétrica (Tabela 1), foram obtidas sementes em $\mathrm{R}_{6}$, com menor valor, comparada aos tratamentos $\mathrm{R}_{7}$ e $\mathrm{R}_{8}$, apesar de serem valores próximos, situação contrária ao observado nos testes de porcentagem de germinação e envelhecimento acelerado, pois, atribuise menores valores de condutividade elétrica as sementes mais vigorosas.

Sá e Lazarini (1995), em sementes com condutividade elétrica abaixo de $60 \mu \mathrm{S} . \mathrm{cm}^{-1} \cdot \mathrm{g}^{-1}$, obtiveram alta porcentagem de emergência no solo, germinação e vigor, contudo neste experimentou observou-se uma alta porcentagem de germinação, mesmo com valores de condutividade elétrica próximos a $100 \mu \mathrm{S} . \mathrm{cm}^{-1} \cdot \mathrm{g}^{-1}$. 
TABELA 1. Valores das médias de porcentagem de germinação (\%), envelhecimento acelerado (\% plântulas normais), comprimento de raiz $(\mathrm{cm})$ e condutividade elétrica $\left(\mu \mathrm{cm}^{-1} \mathrm{~g}^{-1}\right)$, em função dos tratamentos e das cultivares avaliadas.

\begin{tabular}{lllllllll}
\hline \multirow{2}{*}{ Tratamentos } & \multicolumn{4}{c}{ MSOY 6101 } & \multicolumn{3}{c}{ MG/BR 46 (Conquista) } \\
\cline { 2 - 8 } Testemunha & Germ. & E. A. & Raiz & Cond. & Germ. & E. A. & Raiz & Cond. \\
Glifosato & 88 & 66 & 8,1 & 98,7 & 92 & $71 \mathrm{a}$ & 8,5 & $90,1 \mathrm{~b}$ \\
Paraquat & 87 & 65 & 6,8 & 98,7 & 91 & $69 \mathrm{~b}$ & 6,7 & $91,1 \mathrm{a}$ \\
\hline $\mathrm{R}_{6}$ & 87 & 64 & 9,0 & 98,9 & 91 & $71 \mathrm{a}$ & 8,2 & $90,7 \mathrm{ab}$ \\
$\mathrm{R}_{7}$ & $86 \mathrm{~b}$ & 62 & 7,6 & $97,0 \mathrm{~b}$ & -- & -- & -- & -- \\
$\mathrm{R}_{8}$ & $88 \mathrm{a}$ & 66 & 7,9 & $99,5 \mathrm{a}$ & 91 & 69 & 7,6 & 88,8 \\
\hline 2 & $88 \mathrm{a}$ & 68 & 8,3 & $99,8 \mathrm{a}$ & 91 & 71 & 7,9 & 92,4 \\
4 & 88 & 66 & 7,9 & 98,6 & 91 & 69 & 7,4 & 89,5 \\
6 & 88 & 65 & 7,9 & 98,5 & 91 & 71 & 7,8 & 90,2 \\
8 & 87 & 66 & 7,8 & 98,7 & 92 & 71 & 7,8 & 90,2 \\
10 & 88 & 65 & 8,0 & 98,7 & 92 & 70 & 7,8 & 91,3 \\
\hline Ápice & 87 & 65 & 8,0 & 99,4 & 91 & 71 & 8,0 & 91,9 \\
Base & 87 & 65 & $8,0 \mathrm{a}$ & $99,0 \mathrm{a}$ & 91 & 70 & 7,7 & 90,6 \\
\hline CV (\%) & 87 & 65 & $7,9 \mathrm{~b}$ & $98,5 \mathrm{~b}$ & 91 & 71 & 7,8 & 90,6 \\
\hline Média Final & 2,75 & 9,30 & 6,68 & 2,25 & 2,96 & 4,35 & 7,61 & 2,07 \\
\hline
\end{tabular}

${ }^{1}$ Médias seguidas da mesma letra na coluna, não diferem estatisticamente entre si pelo Teste de Tukey aos $5 \%$ de probabilidade.

Y condutividade MSOY 6101 $=98,25375+0,0950694 x \quad r^{2}=0,65$

Y comprimento raiz MG/BR 46 (Conquista) $=7,452708+0,0608542 x \quad r^{2}=0,80$

TABELA 2. Dados referentes ao desdobramento da interação estádio de aplicação $x$ época de amostragem para envelhecimento acelerado na cultivar MSOY 6101.

\begin{tabular}{llllll}
\hline Tratamentos & 2 & 4 & 6 & 8 & 10 \\
\hline $\mathrm{R}_{6}$ & $63 \mathrm{~b}$ & $60 \mathrm{~b}$ & $62 \mathrm{~b}$ & $63 \mathrm{~b}$ & $63 \mathrm{a}$ \\
$\mathrm{R}_{7}$ & $66 \mathrm{ab}$ & $66 \mathrm{a}$ & $68 \mathrm{a}$ & $63 \mathrm{~b}$ & $67 \mathrm{a}$ \\
$\mathrm{R}_{8}$ & $68 \mathrm{a}$ & $69 \mathrm{a}$ & $68 \mathrm{a}$ & $68 \mathrm{a}$ & $65 \mathrm{a}$ \\
\hline
\end{tabular}

${ }^{1}$ Médias seguidas da mesma letra na coluna, não diferem estatisticamente entre si pelo Teste de Tukey aos 5\% de probabilidade.

Não se observou efeito dos herbicidas ou interação entre estes e os demais tratamentos, sobre os parâmetros utilizados para determinar a qualidade fisiológica das sementes. No entanto, Costa et al. (1983), observaram pequena superioridade no vigor das sementes dessecadas, no estádio $R_{7.5}$, com paraquat e atribuíram esta diferença às condições climáticas em que as sementes da colheita normal ficaram submetidas durante a sua permanência no campo.

Na análise estatística dos resultados obtidos na avaliação do comprimento de raiz, obteve-se efeito significativo dos tratamentos de forma isolada e interação entre estes, com exceção para posição de avaliação na planta (Tabela 1).

No desdobramento das interações entre estádio de aplicação x época de amostragem ou dessecantes (Tabela $3)$, verificou-se que nas avaliações realizadas após a aplicação dos herbicidas, com exceção de dois dias após, o comprimento de raiz obtido com o tratamento $\mathrm{R}_{6}$ foi menor que em $R_{8}$. Comportamento bem semelhante foi observado para com o teste de envelhecimento acelerado. $\mathrm{Na}$ avaliação da interação dos estádios de aplicação x dessecantes, novamente o comprimento de raiz em $\mathrm{R}_{8}$ foi superior a $\mathrm{R}_{6}$, com exceção do tratamento testemunha, o que demonstra o efeito residual do tratamento nas 
sementes menos desenvolvidas. Dentro de $\mathrm{R}_{6}$, os resultados de comprimento de raiz, em função das amostragens realizadas, aplicação dos dessecantes e na testemunha, ajustaram-se a uma função quadrática, obtendo-se os menores valores nas avaliações com sementes amostradas aos quatro ou seis dias após a aplicação dos tratamentos. No entanto, em $R_{8}$, os resultados ajustaram-se a uma função linear e crescente, em função das amostragens.

TABELA 3. Dados referentes ao desdobramento da interação dessecante $x$ época de amostragem, dessecante x estádio de aplicação, estádio de aplicação x época de amostragem na cultivar MSOY 6101 para comprimento de raiz $(\mathrm{cm})$.

\begin{tabular}{lllllllll}
\hline \multirow{2}{*}{ Tratamentos } & \multicolumn{4}{c}{ Dias após a dessecação } & \multicolumn{3}{c}{ Estádio de desenvolvimento } \\
\cline { 2 - 9 } & 2 & 4 & 6 & 8 & 10 & $\mathrm{R}_{6}$ & $\mathrm{R}_{7}$ & $\mathrm{R}_{8}$ \\
\hline Testemunha & $8,0 \mathrm{~b}$ & $8,0 \mathrm{~b}$ & $8,0 \mathrm{~b}$ & $8,3 \mathrm{~b}$ & $7,9 \mathrm{~b}$ & $8,3 \mathrm{~b} \mathrm{~A}$ & $8,0 \mathrm{~b} \mathrm{~B}$ & $7,9 \mathrm{~b} \mathrm{~B}$ \\
Glifosato & $6,6 \mathrm{c}$ & $6,6 \mathrm{c}$ & $6,6 \mathrm{c}$ & $7,0 \mathrm{c}$ & $7,2 \mathrm{c}$ & $5,9 \mathrm{c} \mathrm{C}$ & $6,8 \mathrm{c} \mathrm{B}$ & $7,6 \mathrm{c} \mathrm{A}$ \\
Paraquat & $9,0 \mathrm{a}$ & $9,0 \mathrm{a}$ & $8,8 \mathrm{a}$ & $9,0 \mathrm{a}$ & $9,0 \mathrm{a}$ & $8,7 \mathrm{a} \mathrm{B}$ & $9,0 \mathrm{a} \mathrm{AB}$ & $9,2 \mathrm{a} \mathrm{A}$ \\
\hline $\mathrm{R}_{6}$ & $7,8 \mathrm{a}$ & $7,4 \mathrm{~b}$ & $7,4 \mathrm{~b}$ & $7,9 \mathrm{~b}$ & $7,7 \mathrm{~b}$ & --- & --- & --- \\
$\mathrm{R}_{7}$ & $7,9 \mathrm{a}$ & $7,9 \mathrm{a}$ & $8,0 \mathrm{a}$ & $7,9 \mathrm{~b}$ & $7,9 \mathrm{~b}$ & --- & --- & --- \\
$\mathrm{R}_{8}$ & $8,0 \mathrm{a}$ & $8,2 \mathrm{a}$ & $8,0 \mathrm{a}$ & $8,4 \mathrm{a}$ & $8,4 \mathrm{a}$ & --- & --- & --- \\
\hline
\end{tabular}

${ }^{1} \mathrm{Na}$ linha, as médias seguidas pela mesma letra maiúscula e na coluna, pela mesma letra minúscula não diferem estatisticamente entre si pelo Teste de Tukey aos 5\% de probabilidade.

Y glifosato $=6,1516677+0,1054167 x \quad r^{2}=0,967$

Y testemunha $=8,34-0,0391667 x \quad r^{2}=0,276$

$\mathrm{Y} \mathrm{R}_{6}=8,109167-0,1874405 \mathrm{x}+0,01607143 \mathrm{x}^{2} \quad \mathrm{r}^{2}=0,32$

$\mathrm{Y} \mathrm{R}_{8}=8,005+0,0441667 \mathrm{x} \quad \mathrm{r}^{2}=0,57$

Destaca-se com relação aos herbicidas utilizados, o efeito negativo da aplicação do glifosato e o efeito positivo da aplicação do paraquat, nas diferentes épocas de amostragens e estádios de aplicação avaliados. Dentro das épocas de amostragens, o comprimento de raiz ajustou-se a uma função linear e positiva, para o tratamento com glifosato e negativa, apesar de baixo coeficiente de determinação, nas parcelas testemunhas. Mesmo assim, na avaliação aos 10 dias após aplicação do glifosato, o comprimento de raiz das plântulas avaliadas, foi menor em relação à testemunha (Tabela 3).

Funguetto et. al (2004), objetivando estudar metodologias de bioensaios para detecção de sementes de soja tolerantes ao glifosato conduziu três bioensaios baseados no teste de germinação. Concluíram os autores que o glifosato causa anormalidade em plântulas de soja não geneticamente modificadas, apresentando estas, engrossamentos, estrias longitudinais e amarelecimento gradativo do hipocótilo, inibição do desenvolvimento da raiz primária e da emissão de raízes secundárias.

Nesse trabalho, observou-se que o menor valor de comprimento de raiz foi obtido em sementes de plantas que receberam a aplicação do glifosato em $\mathrm{R}_{6}$ (Tabela 3). Isso pode ter ocorrido em função do mesmo ser sistêmico na planta e as sementes ainda estarem em formação, havendo assim translocação do herbicida para as sementes e este ter influenciado negativamente na formação da radícula durante esta avaliação. Situação contrária foi observada no tratamento testemunha.

Avaliando sementes de cultivares de soja resistente ao glifosato enão resistentes, embioensaios compré-embebição em papel toalha ou colocadas diretamente na solução do herbicida, Tillmann e West (2004) verificaram que ambos os métodos são eficientes em identificar genótipos que são resistentes ao glifosato. Os autores utilizaram as avaliações de germinação, comprimento de hipocótilo e total das plantas, concluindo que o glifosato interfere negativamente na germinação e no desenvolvimento inicial das plântulas oriundas de soja não transgênica.

Os resultados obtidos com sementes da cultivar MG/ BR 46 (Conquista), apesar de ter sido aplicado herbicidas somente nos estádios $\mathrm{R}_{7}$ e $\mathrm{R}_{8}$, destaca-se o efeito negativo do tratamento com glifosato, nos testes de envelhecimento acelerado e condutividade elétrica (Tabela 1) e comprimento de raiz (Tabela 4), semelhante ao observado com a cultivar MSOY 6101. 
TABELA 4. Dados referentes ao desdobramento da interação estádio de aplicação $x$ dessecante no comprimento de raiz $(\mathrm{cm})$ para a cultivar MG/BR 46 (Conquista).

\begin{tabular}{llll}
\hline Tratamentos & testemunha & glifosato & paraquat \\
\hline $\mathrm{R}_{7}$ & $8,4 \mathrm{~A}$ & $6,6 \mathrm{C}$ & $7,9 \mathrm{~b} \mathrm{~B}$ \\
$\mathrm{R}_{8}$ & $8,5 \mathrm{~A}$ & $6,7 \mathrm{~B}$ & $8,5 \mathrm{a} \mathrm{A}$ \\
\hline
\end{tabular}

${ }^{1}$ Médias seguidas da mesma letra maiúscula na linha e minúscula na coluna, não diferem estatisticamente entre si pelo Teste de Tukey aos 5\% de probabilidade.

Na cultivar MG/BR 46 (Conquista) não houve diferença significativa para sementes da parte superior (ápice) e inferior (base) da planta, quanto à qualidade fisiológica avaliada (Tabela 1). No entanto, nos estádios onde ocorreu a aplicação dos herbicidas, para todas as avaliações realizadas, observouse interação significativa e geralmente com as épocas de amostragens após a aplicação dos herbicidas, exceção ao comprimento de raiz, onde a interação significativa foi entre estádio de aplicação $\mathrm{x}$ dessecante.

No desdobramento da interação entre estádio de aplicação $\mathrm{x}$ dessecante (Tabela 4) observa-se diferença significativa entre os tratamentos $R_{7}$ e $R_{8}$, somente onde foi aplicado paraquat, e nesse caso, as sementes obtidas com a aplicação no estádio $\mathrm{R}_{8}$, proporcionaram maior desenvolvimento de raiz.

O comportamento das sementes quanto à porcentagem de germinação e envelhecimento acelerado, foi semelhante em função das épocas de amostragens (Tabela 5), ou seja, nas primeiras amostragens, destacam-se como melhores, as sementes obtidas com os tratamentos aplicados em $\mathrm{R}_{8}$ e nas últimas amostragens, ocorreu o contrário. Provavelmente, isso ocorreu devido ao fato de as sementes avaliadas nas aplicações ocorridas em $\mathrm{R}_{8}$ permanecerem mais tempo no campo, ou seja, a primeira amostragem das aplicações em $\mathrm{R}_{8}$ coincidiu com a última amostragem das aplicações em $\mathrm{R}_{7}$. Marcos Filho (1986), referindo-se a vários autores, cita que há sérios prejuízos à qualidade fisiológica de sementes de soja quando estas permanecem desnecessariamente expostas a fatores adversos do ambiente, após a maturação.

$\mathrm{Na}$ avaliação de condutividade elétrica (Tabela 5), observa-se que nas sementes obtidas após aplicação dos herbicidas no estádio $\mathrm{R}_{8}$, independente da época de amostragem, estas apresentaram maior valor de condutividade, demonstrando neste caso, serem sementes de menor vigor.
TABELA 5. Valores referentes desdobramento da interação estádio de aplicação $x$ épocas de amostragem para porcentagem de germinação (\%), envelhecimento acelerado (\% de plântulas normais) e condutividade elétrica $\left(\mu \mathrm{S} \mathrm{cm}^{-1} \mathrm{~g}^{-1}\right)$ para a cultivar MG/ BR 46 (Conquista).

\begin{tabular}{lrrrrr}
\hline \multicolumn{6}{c}{ Porcentagem de germinação } \\
\hline Estádio/dias & 2 & 4 & 6 & 8 & 10 \\
\hline $\mathrm{R}_{7}$ & $90 \mathrm{~b}$ & $90 \mathrm{a}$ & $91 \mathrm{a}$ & $93 \mathrm{a}$ & $93 \mathrm{a}$ \\
$\mathrm{R}_{8}$ & $92 \mathrm{a}$ & $91 \mathrm{a}$ & $92 \mathrm{a}$ & $91 \mathrm{~b}$ & $89 \mathrm{~b}$ \\
\hline \multicolumn{6}{c}{ Envelhecimento acelerado } \\
\hline $\mathrm{R}_{7}$ & $67 \mathrm{~b}$ & $69 \mathrm{~b}$ & $70 \mathrm{a}$ & $69 \mathrm{a}$ & $72 \mathrm{a}$ \\
$\mathrm{R}_{8}$ & $71 \mathrm{a}$ & $72 \mathrm{a}$ & $72 \mathrm{a}$ & $70 \mathrm{a}$ & $69 \mathrm{~b}$ \\
\hline \multicolumn{6}{c}{ Condutividade elétrica } \\
\hline $\mathrm{R}_{7}$ & $88,2 \mathrm{~b}$ & $89,0 \mathrm{~b}$ & $89,0 \mathrm{~b}$ & $88,8 \mathrm{~b}$ & $89,2 \mathrm{~b}$ \\
$\mathrm{R}_{8}$ & $90,7 \mathrm{a}$ & $91,4 \mathrm{a}$ & $91,4 \mathrm{a}$ & $93,8 \mathrm{a}$ & $94,6 \mathrm{a}$ \\
\hline
\end{tabular}

${ }^{1}$ Médias seguidas de mesma letra na coluna, não diferem entre si pelo teste de Tukey aos 5\% de probabilidade.

Quando se realizou a análise de regressão dos resultados de porcentagem de germinação, envelhecimento acelerado e condutividade elétrica, em função das épocas de amostragens, (Tabela 5; Figura 1; Figura 2) verificou-se que as sementes obtidas após aplicação dos tratamentos em $\mathrm{R}_{7}$ proporcionaram valores de porcentagem de germinação e envelhecimento acelerado que se ajustaram a uma função linear crescente, enquanto que, na aplicação dos tratamentos em $\mathrm{R}_{8}$, este ajuste foi para função linear decrescente, quadrático e linear crescente, respectivamente para porcentagem de germinação, envelhecimento acelerado e condutividade elétrica. Isso caracteriza que em $\mathrm{R}_{8}$, com o decorrer das amostragens, após a aplicação dos dessecantes, houve redução da qualidade fisiológica das sementes, em função de maior tempo de permanência no campo.

Em estudo semelhante, com as cultivares Conquista e Tucunaré, Daltro et. al (2010), observaram resultados semelhantes com experimento conduzido em Mato Grosso, onde concluíram que o uso dos herbicidas Paraquat, Diquat e Diuron não afetaram a qualidade fisiológica das sementes de soja, independente do estádio de aplicação, enquanto que o herbicida glifosato, além de prejudicar o desempenho das sementes, provocou fitotoxicidade ao sistema radicular de plântulas de soja, afetando 
negativamente a qualidade das sementes, demonstrando assim que o uso desse herbicida (como dessecante), para a produção de sementes, pode acarretar sérios problemas na qualidade das mesmas e para seu uso.
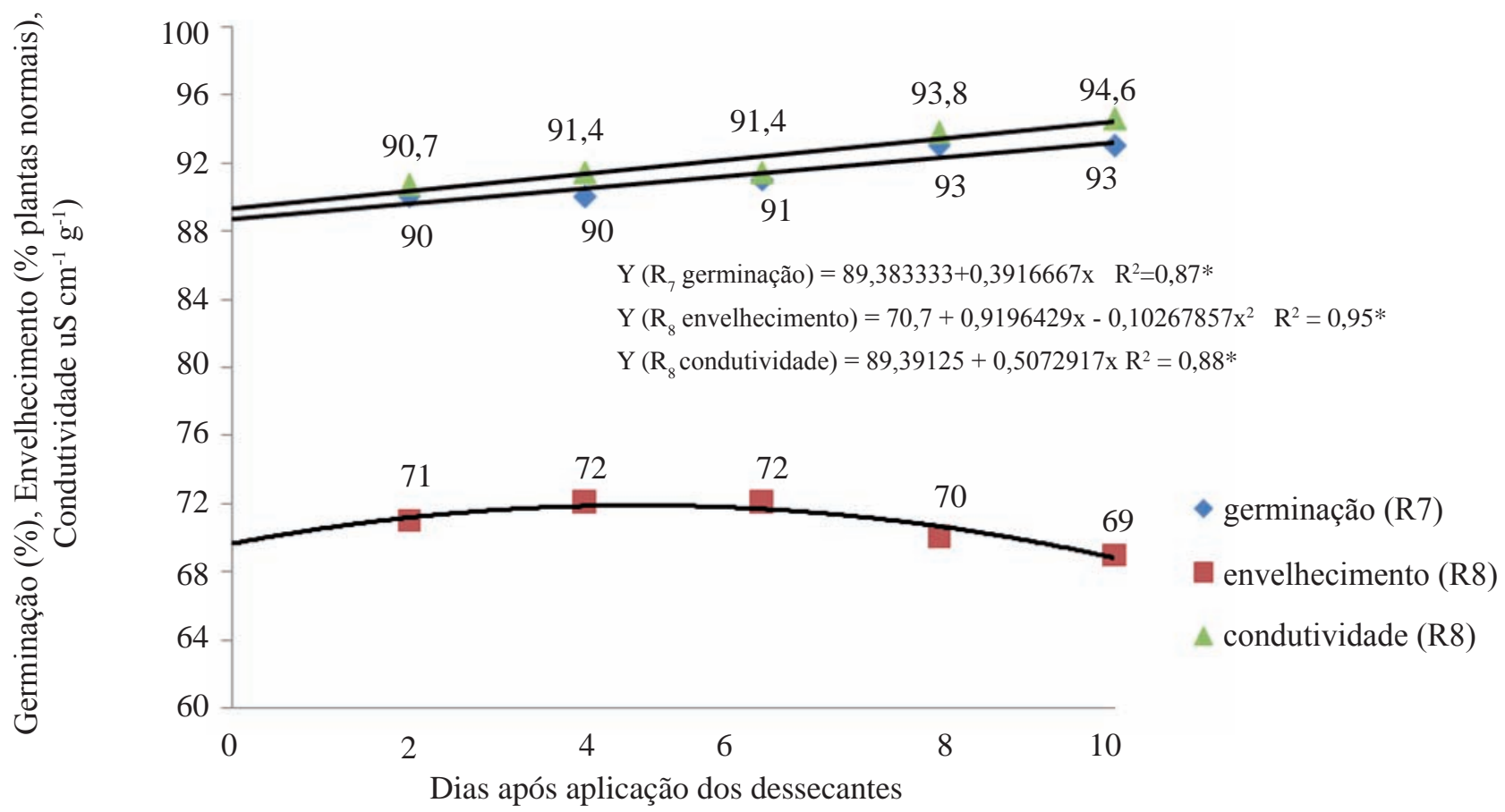

FIGURA 1. Média das regressões de época de amostragem após aplicação dos herbicidas para a qualidade fisiológica das sementes da cultivar MG/BR 46 (Conquista).

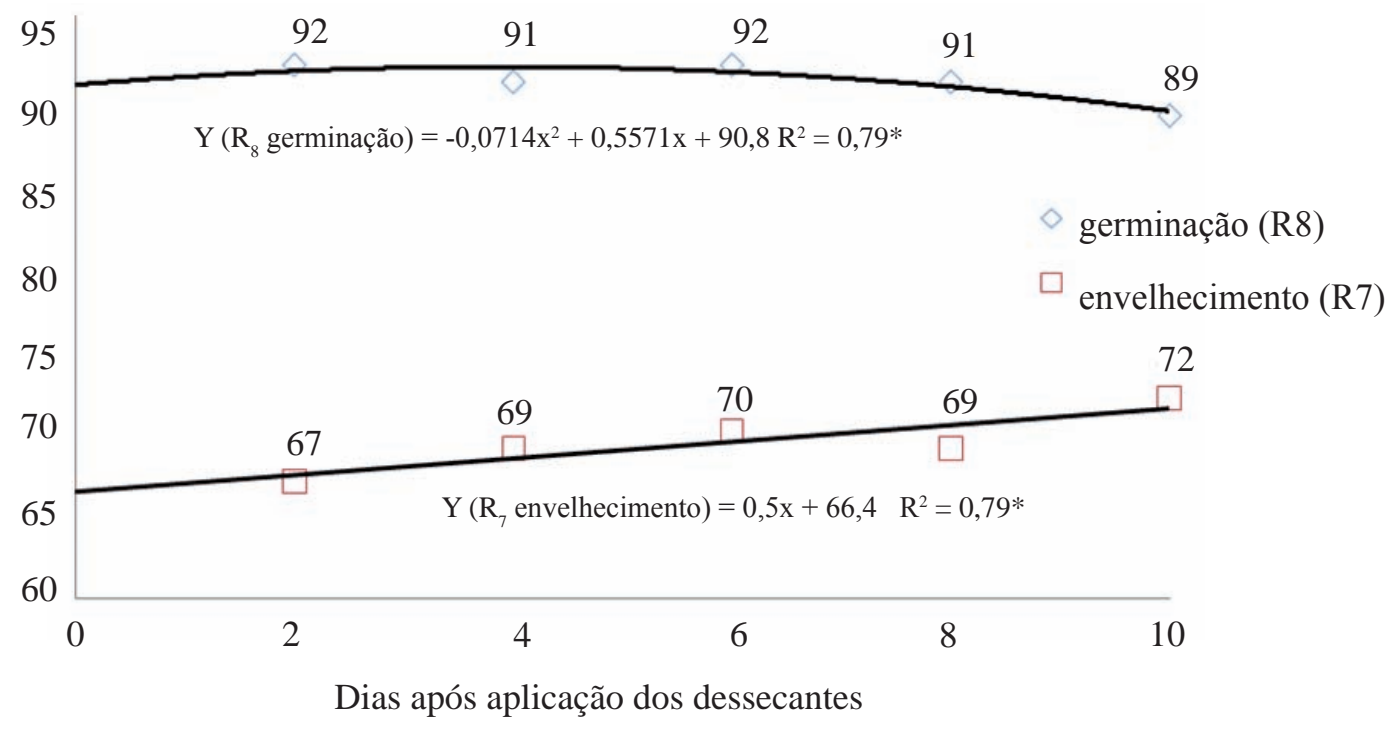

FIGURA 2. Média das regressões de época de amostragem após aplicação dos herbicidas para a qualidade fisiológica das sementes da cultivar MG/BR 46 (Conquista). 


\section{CONCLUSÕES}

A aplicação dos dessecantes influencia, de forma semelhante, a qualidade fisiológica das sementes nas partes das plantas avaliadas (ápice e base);

O glifosato influencia negativamente na qualidade fisiológica das sementes, principalmente quando avaliada pelo teste de comprimento de raiz;

$\mathrm{O}$ paraquat não altera a qualidade fisiológica das sementes;

As sementes obtidas com aplicação de dessecantes no estádio $\mathrm{R}_{6}$ são de qualidade fisiológica inferior às obtidas com aplicação nos estádios $\mathrm{R}_{7}$ e $\mathrm{R}_{8}$.

\section{REFERÊNCIAS}

BASTIDAS, G.; FRANCO, H.; CRUZ, R. de la. Defoliantes en soya (Glycine $\max$ (L.) Merrill). Acta Agronomica, v.21, n.2, p.51-58, 1971.

BRASIL. Ministério da Agricultura e Reforma Agrária. Secretaria Nacional deDefesa Agropecuária. Departamento Nacional de Produção Vegetal. Coordenação de Laboratório Vegetal. Regras para Análise de Sementes. Brasília, DF, 1992. 365p.

COSTA, N.P.; FRANÇA NETO, J.B.; PEREIRA, L.A.G.; HENNING, A.A.; TURKIEWICZ, L.; DIAS, M.C.L. Antecipação de colheita de sementes de soja através do uso de dessecantes. Revista Brasileira de Sementes, v.5, p.183-198, 1983.

COSTA, N.P.; MESQUITA, C. M.; MAURINA, A.C.; FRANÇA NETO, J.B.; KRZYZANOWSKI, F.C.; HENNING, A.A. Qualidade fisiológica, física e sanitária de sementes de soja produzidas no Brasil. Revista Brasileira de Sementes, v.25, n.1, p.128-132, 2003.

DALTRO, E.M.F.; ALBUQUERQUE, M.C.F.; FRANÇA NETO, J.B.; GUIMARÃES, S.C.; GAZZIERO, D.L.P.; HENNING, A.A. Aplicação de dessecantes em précolheita: efeito na qualidade fisiológica de sementes de soja. Revista Brasileira de Sementes, v.31, n.1, 2010.

DELOUCHE, J.C. Seed maturation. In: Handbook of Seed Technology. State College: Mississipi: Mississipi State University, 1971. p.17-21.

EMBRAPA SOJA. Tecnologias de produção de soja - Região Central do Brasil, 2005. Londrina: Embrapa Soja, Embrapa Cerrados, Embrapa Agropecuária Oeste, Fundação Meridional, 242p. 2005. (Embrapa Soja. Sistema de Produção, 6).
EMBRAPA SOJA. Soja em números (safra 2008/2009). Site da Embrapa Soja. Disponível em: $<$ http://www.cnpso. embrapa.br/index.php?cod_pai=2\&op_page $=294>$. Acesso em: 28 de ago. 2010.

FEHR, W.R.; CAVINESS, C.E.; VORST, J.J. Response of indeterminate and determinate soybean cultivares to defoliation and half-plant cut-off. Crop Science, v.17, p.913-17, 1977.

FUNGUETTO, C.I.; TILLMANN, M.A.A.; VILLELA, F.A.; DODE, L.B. Detecção de sementes de soja geneticamente modificadas tolerantes ao herbicida glifosato. Revista Brasileira de Sementes, v.26, n.1, p.130-138, 2004.

GOMES, J.L.L. Efeito da aplicação de gramoxone e do reglone sobre a incidência de patógenos nas sementes de soja. In: CONGRESSO BRASILEIRO DE FITOPATOLOGIA, 15., 1982, São Paulo. Resumos... São Paulo: Sociedade Brasileira de Fitopatologia, 1982.

GOMES, J. C.; SOARES, L. F.; PEREIRA, C. A.; JHAM, G. N. Efeito do dessecante paraquat na qualidade da fração lipídica da soja. Ciência e Agrotecnologia, v.27, n.1, p.178-184, 2003.

HAMER, E. Maturação de sementes de soja no trópico úmido. 1999. 58f. Tese (Doutorado em Ciência e Tecnologia de Sementes) - Universidade Federal de Pelotas, Pelotas, 1999.

HAMMERTON, J.L. Effects of weed competition, defoliation and time of harvest on soybeans. Experimental Agriculture, v.8, p.333-38, 1972.

INOUE, M. H.; MARCHIORI, O.; BRACCINI, A. L.; OLIVEIRA, R. S.; AVILLA, M. R. Rendimento de grãos e qualidade de sementes de soja após a aplicação de herbicidas dessecantes. Ciencia Rural, v.33, n.4, p.769770, 2003.

LACERDA, A.L.S.; LAZARINI, E.; SÁ, M.E.; VALÉRIO FILHO, W.V. Armazenamento de sementes de soja dessecadas e avaliação da qualidade fisiológica, bioquímica e sanitária. Revista Brasileira de Sementes, v.25, n.2, p.97-105, 2003.

LACERDA, A. L. S.; LAZARINI, E.; SÁ, M. E.; VALTER FILHO, V. V. Efeitos da dessecação de plantas de soja no potencial fisiológico e sanitário das sementes. Bragantia, v.64, n.3, 2005.

MARCOS FILHO, J. Produção de sementes de soja. Campinas: Fundação Cargill,1986. 86p.

MARCOS FILHO, J. Testes de vigor: importância e 
utilização. In: KRZYZANOWSKI, F.C.; VIEIRA, R.D., FRANÇA NETO, J.B. (Ed.). Vigor de sementes: conceitos e testes. Londrina: ABRATES, 1999. cap.1, p.1-21

MARCOS FILHO, J. Fisiologia de sementes de plantas cultivadas. Piracicaba: FEALQ, 2005. 495p.

MENEZES, S. M.; TILLMANN, M. A. A.; VILLELA, F. A. Detecção de soja geneticamente modificada tolerante ao glifosato por métodos baseados na atividade de enzimas. Revista Brasileira de Sementes, v.26, n.2, p.150-155, 2004.

MIRANDA, L.C.; DA SILVA,W.R.; CAVARIANI, C. Secagem de sementes de soja em silo com distribuição radial do fluxo de ar. I. Monitoramento físico. Pesquisa Agropecuária Brasileira, v.34, n.11, p.2097-2108, 1999.

NAKAGAWA, J. Testes de vigor baseados no desempenho das plântulas. In: KRZYZANOWSKI, F.C.; VIEIRA, R.D.; FRANÇA-NETO, J.B. Vigor de sementes: conceitos e testes. Londrina: ABRATES, 1999. Cap.2, p.9-13.
SÁ, M.E., LAZARINI, E. Relação entre os valores de condutividade elétrica e níveis de emergência em sementes de diferentes genótipos de soja. Informativo Abrates, v.5, p.143, 1995.

TILLMANN, M.A.A.; WEST, S. Identificação de sementes de soja geneticamente modificada resistente ao glifosato. Scientia Agricola, v.26, n.3, p. 336-341, 2004.

VEIGA,A.D.;ROSA, S.D.V.F.; SILVA, P.A., OLIVEIRA, J.A.; ALVIM, P.O., DINIZ, K.A. Tolerância de sementes de soja à dessecação. Ciência e Agrotecnologia, v.31, n. 3, 2007.

WHIGHAM, D.K.; STOLLER, E.W. Soybean desiccation by paraquat, glyphosate and ametryn to accelerate harvest. Agronomy Journal, v.71, p.630-633, 1979.

ZONTA, E.P. ; MACHADO, A.A. SANEST: sistema estatístico para microcomputadores. Pelotas: UFPEL, 1991. 120p. 